\title{
Morphological Behavior of DPPC-DMPC Two-dimensional Mixed Monolayer on Water Surface by Dropping Method
}

Yuta Watanabe, Daiki Uchida, Honoka Akatsuka, Akihiro Yoshino, Keijiro Taga, Yasushi Yamamoto, Zameer Shervani, and Masato Yamamoto

\section{ABSTRACT}

We have investigated the morphology of dipalmitoyl phosphatidyl choline (DPPC)-dimyristoyl PC (DMPC) mixed monolayer formed on the water surface by the dropping method using surface tension measurement (STm), Brewster angle microscopy (BAM), and infrared external reflection spectroscopy (IERS). The limiting molecular area $\left(A_{0}\right)$ obtained by STm showed that the negative deviation at $<$ mole fraction $\left(x_{D M P C}\right)=$ 0.4 whereas the positive deviation at $>x_{D M P C}=0.6$ when DMPC was added to the DPPC monolayer. BAM images also showed that the condensed rigid monolayer at $x_{D M P C}<0.4$ changed to the expandable monolayer at $x_{D M P C}>0.5$. Moreover, IER spectra showed that the alkyl chains of both DPPC and DMPC molecules are in trans conformation in mixed monolayer at $x_{D M P C}=0.2$ whereas gauche conformation existed at $x_{D M P C}=$ 0.8. Above findings have justified the transition of flexible gauche conformation alkyl chains of DMPC molecule into rigid trans conformation by the addition of DPPC molecule at $x_{D M P C}<0.4$ whereas alkyl chains retained flexible gauche conformation in both DPPC and DMPC molecules at $x_{D M P C}>0.6$.

Keywords: Dipalmitoyl Phosphatidyl Choline (DPPC); Dimyristoyl Phosphatidyl Choline (DMPC); Mixed Monolayer; Surface Tension Measurement (STm); Brewster Angle Microscopy (BAM); Infrared External Reflection Microscopy (IERS).

Published Online: February 09, 2022

ISSN: $2684-4478$

DOI: $10.24018 /$ ejchem.2022.3.1.75

\section{Yuta Watanabe}

Department of Life Science and Applied Chemistry, Graduate School of Engineering, Nagoya Institute of Technology, Nagoya, Japan.

Daiki Uchida

Department of Life Science and Applied

Chemistry, Graduate School of

Engineering, Nagoya Institute of

Technology, Nagoya, Japan.

Honoka Akatsuka

Department of Life Science and Applied Chemistry, Graduate School of Engineering, Nagoya Institute of Technology, Nagoya, Japan.

Akihiro Yoshino

Department of Life Science and Applied Chemistry, Graduate School of Engineering, Nagoya Institute of Technology, Nagoya, Japan.

Keijiro Taga

Department of Life Science and Applied Chemistry, Graduate School of Engineering, Nagoya Institute of Technology, Nagoya, Japan.

Yasushi Yamamoto*

Department of Life Science and Applied Chemistry, Graduate School of Engineering, Nagoya Institute of Technology, Nagoya, Japan.

(e-mail: yamamoto.yasushi@nitech.ac.jp) Zameer Shervani*

Food \& Energy Security Research \& Product Centre, Sendai, Japan. (e-mail: shervani.nanotek@ gmail.com) Masato Yamamoto Department of Chemistry, School of Arts and Sciences, Showa University, Fujiyoshida, Japan.

*Corresponding Author

\section{INTRODUCTION}

Biomembrane is an important part of cell organelles enclosing different cell components and performs a number of functions important to keep cell alive and functioning. It separates the intracellular space from outside, maintains a balance between internal and external state of the cell, exchanges information between cells and transports specific functional substances necessary for cell and organelles functioning. The main components of biomembranes are lipids and membrane-protein present in various ratios depending on the type of membrane [1]. 'Fluid mosaic model', proposed by Singer and Nicolson, has 
been widely accepted as a basic structure of biomembrane [2]. In this model, functional membrane proteins are buried in lipid-bilayers consisting of various kinds of lipids in the mosaic pattern. Lipids and proteins move freely in bilayer giving fluidic nature to bilayer structure. Phospholipids are main biomembrane's components with glycolipids and cholesterol the other two important molecules involve in signal transduction in vivo [1].

The molecular structure of phospholipid molecule comprises of hydrophilic phosphate ester moieties and two alkyl chains as a hydrophobic group. So, phospholipid molecule shows amphiphilic properties and works as a bio-surfactant. In water subphase, stable lipid bilayers structures of vesicles are formed by orienting hydrophilic moieties outside exposing to water and alkyl hydrophobic chains are aggregated inside avoiding water phase. At air/water interface, stable lipid monolayer is formed when hydrophobic alkyl chains are oriented toward the air phase and hydrophilic moieties spread toward the water phase. Because of the unique properties of forming monolayer and bilayer, the phospholipid molecules are widely used to prepare and study the model biomembrane for a number of purposes [3], [4]. Dipalmitoyl phosphatidyl choline (DPPC) and dimyristoyl PC (DMPC) used in this research are typical phospholipids composed of two alkyl chains (C16 for DPPC and C14 for DMPC) and a polar phosphatidyl choline and glycerol-carbonyl moiety as hydrophilic group. The two phospholipids DPPC and DMPC have a slight structural difference. They are widely used to prepare and study the model biomembranes [4]-[6] in the form of gel/liquid-crystal phase transition of bilayers in water and expand/condensation transition of monolayer on the water surface. There is a difference of only two carbon atoms in the alkyl chain between DPPC and DMPC molecules. This small difference greatly affects the properties of the two molecules. For example, gel/liquid-crystal phase transition of DPPC is $41^{\circ} \mathrm{C}$ and that of DMPC is $24^{\circ} \mathrm{C}$.

In mixed DPPC-DMPC multilamellar phase diagram in water the preferential appearance of gel or liquid crystal phase depends on the mole fractions of each lipid and at specific mole fraction and temperature the two phases coexist [7]-[11]. Apart from multilamellar phase, the DPPC-DMPC twodimensional mixed monolayer on water surface can be investigated from the viewpoint of observing the changes in monolayer versus mole fractions of the two lipids. The mixed monolayers of other lipids distearoyl phosphatidyl choline (DSPC)-DMPC [12], [13], DSPC-DPPC [14], and DPPC-hexadecanol [15] have been investigated. However, the study of DPPC-DMPC lipid combination is a pending issue. Therefore, in this communication, we have investigated the monolayer properties of two-dimensional DPPC-DMPC mixed monolayer at various mole fractions formed by the dropping method [16], [17], [18], [19] using surface tension measurement (STm), Brewster angle microscopy (BAM), and infrared external reflection spectroscopy (IERS).

\section{EXPERIMENTAL}

\section{A. Materials}

Dipalmitoyl phosphatidyl choline (DPPC, purity: >99\%), dimyristoyl phosphatidyl choline (DMPC, purity: >99\%), and dimyristoyl-d54 phosphatidyl choline (DMPC (d), purity >99\%) were purchased from Avanti polar lipids Inc. (Alabama, USA), respectively, and these were used without further purification. Spreading solvent used for monolayer preparation was chloroform $(99.0 \%$, Wako Pure Chemical Industries Ltd.). Purified water with conductance $<0.07 \mu \mathrm{S} / \mathrm{cm}$ was obtained using a Super Water Purifying System (WL-21P; Yamato Scientific Corp. Ltd.).

\section{B. Monolayer Formation}

Lipids DPPC, DMPC and DMPC(d) were dissolved in chloroform to prepare dropping solutions of 0.5 $\mathrm{mM}$. The dropping solution of pure DPPC, DMPC, DMPC(d) and mixed lipids, depending on the experiment, was dropped on a purified water surface with a $100 \mu \mathrm{l}$ microsyringe (Ge-0583-04; Hamilton Corp., Nevada, USA) to prepare the monolayer. The experimental details of monolayer formation have been reported previously [16]-[20]. Initially, $1 \mu \mathrm{l}$ drop of dropping solution was spread gently on the water surface and next drop was added after $\geqq 1$ min so that previous droplet expanded sufficiently on the water surface. After the addition of each drop of dropping solution containing lipid molecules on the water surface, the attainment of molecular expansion equilibrium was confirmed by surface tension (Section II-III) value till it becomes constant. The completion of monolayer formation was confirmed by the appearance of lens and a constant value of surface tension.

\section{Surface Tension Measurement (STm)}

Surface tension measurement (STm) for each pure DPPC, DMPC, DMPC (d)) and several mixed monolayers were carried out using a Surface Tensiometer (CBVP-A3; Kyowa Interface Science Corp. Ltd., Saitama, Japan) with a platinum Wilhelmy plate [16]-[20]. Surface tension was recorded after 
spreading each drop at $26 \pm 1^{\circ} \mathrm{C}$. The value of surface tension was converted to surface pressure $(\pi)$. The $\pi$ - $A$ curve of each monolayer was constructed as a function of the dropping volume (molecule numbers).

\section{Brewster Angle Microscopy (BAM)}

Brewster angle microscopy (BAM) for visualizing the morphology of pure DPPC and DMPC and several mixed monolayers were carried out using a commercial BAM microscope (EMM633K; Filgen Inc., Nagoya, Japan) attached with an USB-CAP type (GV-USB2; I-O DATA DEVICE, INC., Kanazawa, Japan) imaging analysis software [16], [17], [18], [19], [20]. BAM shows the monolayer image arises from the difference in refractive index between the monolayer and the water phase. BAM device was mounted on a glass dish and $p$-polarized light of $632.8 \mathrm{~nm}$ wavelength from a $10 \mathrm{~mW} \mathrm{He}-\mathrm{Ne}$ laser was irradiated at the Brewster angle of $53.1^{\circ}$ on the surface of pure and mixed monolayers. The reflected light was magnified with a $40 \mathrm{~mm}$ focal length lens and detected by a CCD camera (C5948-70; Hamamatsu Photonics, Hamamatsu). The formation of pure and mixed monolayers prepared by dropping method was observed in real-time at $26 \pm 1^{\circ} \mathrm{C}$. The lateral resolution of BAM image was about $1 \mu \mathrm{m}$.

\section{E. Infrared External Reflection Spectroscopy (IERS)}

The structure of alkyl chains of DPPC and DMPC molecules in two mixed monolayers consisting of mole fraction of DMPC: $0.2,0.8$ and mole fraction of DMPC(d): 0.2 were studied by infrared external reflection spectroscopy (IERS) [16], [18], [19], [21]. An FT-IR spectrometer (FT-IR-600Plus; JASCO Int. Co. Ltd.) fitted with a liquid-nitrogen-cooled MCT detector and a reflectance apparatus was employed in combination. Dropwise added DPPC-DMPC/chloroform solution was expanded on the water surface in a poly(tetrafluoroethrene) trough $\left(20 \times 62 \mathrm{~mm}^{2}\right)$ at room temperature, according to the dropping method as described in Section 2.2. IERS measurement of mixed monolayer at $\pi=40 \mathrm{mN} / \mathrm{m}$ was conducted. $p$ polarized IR light at incident angles of $8-10^{\circ}$ and $70-75^{\circ}$ was irradiated on each mixed monolayer and reflected light was detected by MCT detector to investigate molecular structure and their orientation. More than 1000 scans were averaged with a resolution of $4 \mathrm{~cm}^{-1}$. The IER spectra were converted to the absorption spectra ( $k$-spectra) by the reported method [14] using Lorentz oscillator model (LOM) calculation under the assumptions of the $n_{\infty}$ values (the real part of complex refractive index) of the limiting of the high-wavenumber are 1.50 and the thickness of each mixed monolayer is $2.3 \mathrm{~nm}$.

\section{RESULTS AND DISCUSSION}

\section{A. $\pi$-A Isotherm Curve}

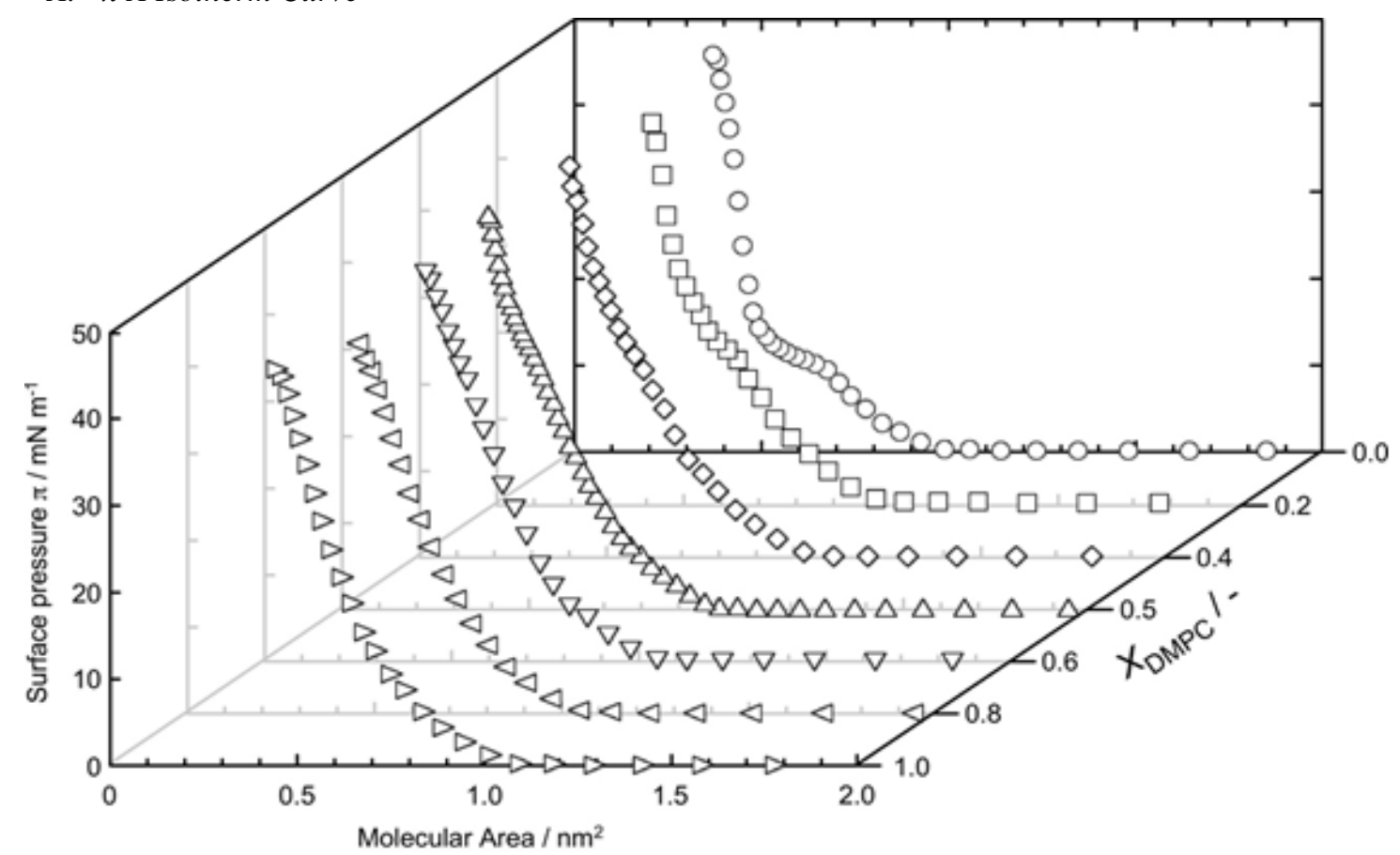

Fig. $1 \pi$ - $A$ isotherm curves of various DPPC-DMPC mixed monolayers in DMPC mole fraction $x_{D M P C}=0.0,0.2,0.4,0.5,0.6,0.8$, and 1.0 on the water surface at $26^{\circ} \mathrm{C}$ using the dropping method.

Fig. 1 shows $\pi$ versus molecular area $A(\pi-A)$ isotherm curves of various DPPC-DMPC mixed monolayers (DMPC mole fraction $x_{D M P C}=0.0,0.2,0.4,0.5,0.6,0.8,1.0$ ) on water surface at $26^{\circ} \mathrm{C}$ constructed by dropping method. Horizontal axis represents $A$ calculated from molecular numbers in the 
dropping volume, vertical axis is $\pi$ recorded after dropping the sample solution on the water surface, and depth axis is $x_{D M P C}$. When $\pi$ reached at constant value after dropping each droplet, $\pi$ value was recorded.

At pure DPPC monolayer $\left(x_{D M P C}=0.0,(O)\right), \pi$ value increased gradually from molecular area > $1.0 \mathrm{~nm}^{2}$. It was Liquid-Expanded (LE) state till molecular area $>1.0 \mathrm{~nm}^{2}$. After a transition from LE to Liquid-Condensed (LC) states was observed around $10 \mathrm{mN} / \mathrm{m}$ (plateau range), the $\pi$ increased up to $45 \mathrm{mN} / \mathrm{m}$. The limiting molecular area $\left(A_{0}\right)$ of $x_{D M P C}=0.0$ was $0.58 \pm 0.02 \mathrm{~nm}^{2} / \mathrm{molecule}(40 \mathrm{mN} / \mathrm{m})$. This curve was similar to that previously reported [16]-[18], [20]. and also different from that by the compression method [6], [22]. As recorded by compression method [22], the maximum $\pi$ and $A_{0}$ were $50 \mathrm{mN} / \mathrm{m}$ and $0.48 \mathrm{~nm}^{2} /$ molecule, respectively. Compared with the compression method, the maximum $\pi$ was $10 \%$ lower and $A_{0}$ was $20 \%$ larger to the values we recorded by dropping method. A lower $\pi$ value and larger $A_{0}$, suggest the formation of "semi-expanded state" type DPPC monolayer on the water surface which has "fluid structure" where hydrophilic groups (phosphatidyl choline) of DPPC molecules and water molecules are arranged in most comfortably through hydrogen bonding also known as hydrophilic interaction [16].

At the pure DMPC monolayer $\left(x_{D M P C}=1.0,(\triangleright)\right)$, the $\pi-A$ isotherm curve was almost the same as reported previously [17], [23], [24]. $\pi$ increased gradually from a molecular area $>1.0 \mathrm{~nm}^{2}$ and kept increasing monotonously up to $45 \mathrm{mN} / \mathrm{m}$. The shape of the curve was smooth and similar to that obtained by compression method [6], [25], [26]. $A_{0}$ and $\pi$ values for $x_{D M P C}=1.0$ were $0.75 \pm 0.03 \mathrm{~nm}^{2} / \mathrm{molecule}$ and $40 \mathrm{mN} / \mathrm{m}$, respectively similar to the values $\left(0.73 \mathrm{~nm}^{2} /\right.$ molecule and $40 \mathrm{mN} / \mathrm{m}$, respectively) obtained by compression method. The recorded $A_{0}$ and $\pi$ values for $x_{D M P C}=1.0$ suggested DMPC monolayer is in LE state where two alkyl chains of DMPC molecule were partially disordered. The alkyl chains are in gauche conformation and the cross-sectional area would be larger than that of hydrophilic group of DMPC molecule.

Comparing the pure DPPC monolayer $\left(x_{D M P C}=0.0,(O)\right)$, the shape of $\pi-A$ isotherm curves of DPPCDMPC mixed monolayer changed gradually with the increase in mole fraction of DMPC (from 0.2 to 0.8 ) as following. At $x_{D M P C}=0.2(\square)$, the $\pi$ increased gradually from a molecular area $>1.0 \mathrm{~nm}^{2}$ similar to $x_{D M P C}=0.0$. Though, the plateau region observed at $x_{D M P C}=0.0$ did not exist. Instead, the curve bent at $15 \mathrm{mN} / \mathrm{m}$ and after that increased linearly. From $22 \mathrm{mN} / \mathrm{m}$ onward the $\pi$ increased to $44 \mathrm{mN} / \mathrm{m}$. $A_{0}$ of $x_{D M P C}=0.2$ was $0.57 \pm 0.01 \mathrm{~nm}^{2} /$ molecule at $40 \mathrm{mN} / \mathrm{m}$ which was almost the same as of DPPC monolayer. At $x_{D M P C}=0.4(\diamond)$, the curve was little different from that of $x_{D M P C}=0.2$. and $0.0 . \pi$ increased gradually from a molecular area $>1.0 \mathrm{~nm}^{2}$ same as for $x_{D M P C}=0.2$ and 0.0 . The bending of the curve was observed at $16 \mathrm{mN} / \mathrm{m}$ and then increased linearly. The slope of the linear increase for $x_{D M P C}=0.4$ was larger than for $x_{D M P C}=0.2$. $\pi$ increased steeply from $32 \mathrm{mN} / \mathrm{m}$ to $45 \mathrm{mN} / \mathrm{m}$. $A_{0}$ of $x_{D M P C}=0.4$ was $0.64 \pm 0.02 \mathrm{~nm}^{2} /$ molecule at $40 \mathrm{mN} / \mathrm{m}$ and the value of $A_{0}$ was larger than those of $x_{D M P C}=0.0$ and 0.2 . At $x_{D M P C}=0.5(\triangle)$, the curve was close to that of $x_{D M P C}=0.4$ and $A_{0}$ was also the same as that of $x_{D M P C}=0.4$ $\left(0.66 \pm 0.02 \mathrm{~nm}^{2} / \mathrm{molecule}(40 \mathrm{mN} / \mathrm{m})\right)$. At $x_{D M P C}=0.6(\nabla)$, the curve was a little different from those of $<x_{D M P C}=0.5 . \pi$ increased gradually from molecular area $>1.0 \mathrm{~nm}^{2}$ and the curve bent at $34 \mathrm{mN} / \mathrm{m}$. After that $\pi$ increased steeply from 38 to $45 \mathrm{mN} / \mathrm{m}$. $A_{0}$ for $x_{D M P C}=0.6$ was $0.76 \pm 0.02 \mathrm{~nm}^{2} / \mathrm{molecule}$ at 40 $\mathrm{mN} / \mathrm{m}$ which was close to the DMPC monolayer. At $x_{D M P C}=0.8(\triangleleft)$, the curve was different from those of $\left\langle x_{D M P C}=0.6\right.$ and very similar to $x_{D M P C}=1.0 . \pi$ increased gradually from a molecular area $>1.0 \mathrm{~nm}^{2}$ and further increased monotonously up to $43 \mathrm{mN} / \mathrm{m}$. The shape of curve was as smooth as that of $x_{D M P C}=$ 1.0. $A_{0}$ for $x_{D M P C}=0.8$ was also $0.77 \pm 0.02 \mathrm{~nm}^{2} /$ molecule at $40 \mathrm{mN} / \mathrm{m}$ and it was close to that of DMPC monolayer. These results suggested that the formation of DPPC-DMPC mixed monolayer was very different for each mole fraction $\left(x_{D M P C}\right)$ of DMPC.

\section{B. Brewster Angle Microscopy (BAM)}

Fig. 2 shows a series of BAM images of DPPC-DMPC mixed monolayers in DMPC mole fraction ratios $x_{D M P C}=0.0,0.2,0.4,0.5,0.6,1.0$ on the water surface at $26^{\circ} \mathrm{C}$. Fig. $2 \mathrm{a}-\mathrm{c}, 2 \mathrm{~d}-\mathrm{f}, 2 \mathrm{~g}-\mathrm{I}, 2 \mathrm{j}-1,2 \mathrm{~m}-\mathrm{O}$, and $2 \mathrm{p}-\mathrm{r}$ are DPPC-DMPC mixed monolayer of $x_{D M P C}=0.0,0.2,0.4,0.5,0.6$, and 1.0 respectively. BAM observation was performed on each monolayer at the dropping volume corresponding to three $\pi$ values as shown in the inset of the figures.

At the DPPC monolayer of $x_{D M P C}=0.0$ (Fig. 2a-c), images resembled with those previously reported [16]-[18]. Image $2 \mathrm{a}$ at $\pi=4.1 \mathrm{mN} / \mathrm{m}$ is of the monolayer before LE-LC transition and showed a homogeneous dark contrast. Image $2 \mathrm{~b}$ of $\pi=10.5 \mathrm{mN} / \mathrm{m}$ around LE-LC transition is the monolayer where phases (LE and LC phase) coexist and showed hole-type dark parts in bright domain (spot-type pattern). This pattern was different from that by the compression method [27]. Image $2 \mathrm{c}$ of $\pi=42.3 \mathrm{mN} / \mathrm{m}$ is the monolayer after LE-LC transition and showed a homogeneous bright contrast. These images indicate that fluidic DPPC monolayer in "semi-expanded state" type domain was formed on the water surface by the dropping method. This result also corresponded to that obtained by the $\pi-A$ isotherm curve (Fig. 1 (०)). 

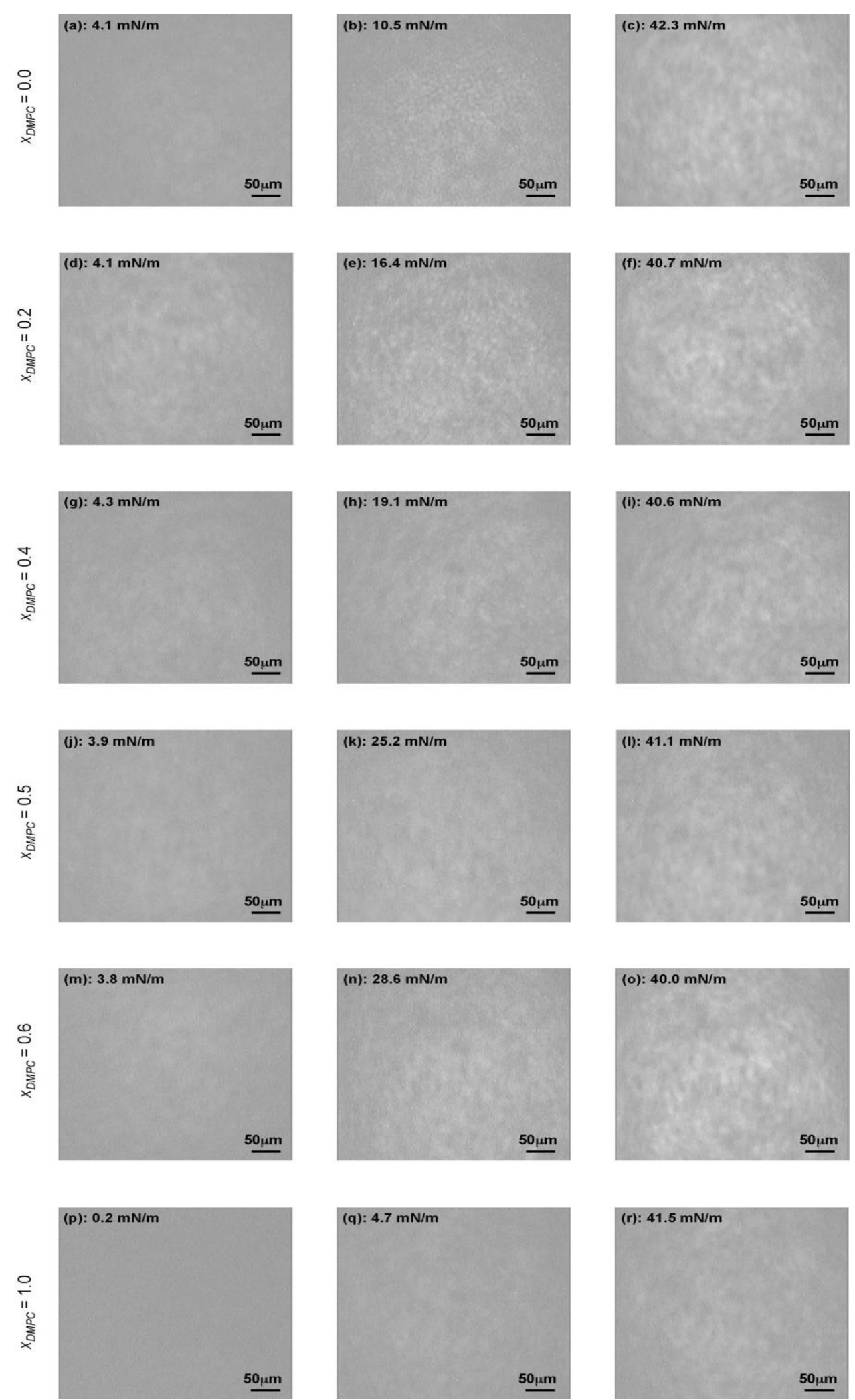

Fig. 2. BAM images of various DPPC-DMPC mixed monolayers (DMPC mole fraction $\mathrm{x}_{\mathrm{DMPC}}=0.0,0.2,0.4,0.5,0.6$, and 1.0 ) on the water surface at $26{ }^{\circ} \mathrm{C}$. $\mathrm{x}_{\mathrm{DMPC}}$ of (a-c) 0.0 (pure DPPC monolayer); (d-f) 0.2 ; (g-i) 0.4 ; (j-1) 0.5 ; (m-o) 0.6; and (p-r) 1.0 (pure DMPC monolayer).

At the DMPC monolayer of $x_{D M P C}=1.0$ (Fig. 2p-r), images resembled with those previously reported [17], [24]. Image $2 p$ of $\pi=0.2 \mathrm{mN} / \mathrm{m}$ showed a homogeneous dark contrast. With increasing in $\pi$, the image became bright. Image $2 q$ of $\pi=4.7 \mathrm{mN} / \mathrm{m}$ was brighter than image $2 p$ of $\pi=0.2 \mathrm{mN} / \mathrm{m}$, indicated that DMPC monolayer continued to form homogeneously. Image $2 \mathrm{r}$ of $\pi=41.5 \mathrm{mN} / \mathrm{m}$ showed still brighter homogeneous contrast. The pattern of these three images indicated that expandable DMPC monolayer was formed on the water surface by the dropping method. The result also corresponded to that obtained by $\pi-A$ isotherm curve (Fig. $1(\triangleright)$ ) and was the same as reported previously by the compression 
method [28].

BAM images of DPPC-DMPC mixed monolayer changed gradually according to an increase in the mole fraction of DMPC (from 0.2 to 0.8 ) as following. At $x_{D M P C}=0.2$ (Fig. $2 \mathrm{~d}-\mathrm{f}$ ), the images resembled with those of pure DPPC monolayer. Image $2 \mathrm{~d}$ of $\pi=4.1 \mathrm{mN} / \mathrm{m}$ showed a homogeneous dark contrast. Image $2 \mathrm{e}$ of $\pi=16.4 \mathrm{mN} / \mathrm{m}$ showed a coexistence state that has hole-type dark parts bright domain (spottype pattern). The image resembled with image $2 b$ of pure DPPC monolayer. From the image, it was found that the slope of the isotherm curve from 15 to $22 \mathrm{mN} / \mathrm{m}$ in Fig. 1( $\square$ ) indicated LE-LC transition of mixed monolayer at $x_{D M P C}=0.2$. Image $2 \mathrm{f}$ of $\pi=40.7 \mathrm{mN} / \mathrm{m}$ showed a homogeneous bright contrast. At $\mathrm{x}_{\mathrm{DMPC}}=0.4$ (Fig. $2 \mathrm{~g}-\mathrm{i}$ ), the images were a little different from those of $\mathrm{x}_{\mathrm{DMPC}}=0.2$. Image $2 \mathrm{~g}$ of $\pi=4.3$ $\mathrm{mN} / \mathrm{m}$ showed a homogeneous dark contrast. Image $2 \mathrm{~h}$ of $\pi=19.1 \mathrm{mN} / \mathrm{m}$ showed brighter image than that of $\pi=4.3 \mathrm{mN} / \mathrm{m}$ (image $2 \mathrm{~g}$ ). The image also showed slightly spot-type pattern as observed at image $2 \mathrm{e}$ of $\mathrm{x}_{\mathrm{DMPC}}=0.2$, but it was less clear. Image 2i showed a homogeneous bright contrast. At $\mathrm{x}_{\mathrm{DMPC}}=0.5$ (Fig. $2 \mathrm{j}-1$ ), images were different from those of $\mathrm{x}_{\mathrm{DMPC}}=0.2$ and 0.4 . Image $2 \mathrm{j}$ of $\pi=3.9 \mathrm{mN} / \mathrm{m}$ showed a homogeneous dark contrast. Image $2 \mathrm{k}$ of $\pi=25.2 \mathrm{mN} / \mathrm{m}$ showed brighter image than that of $\pi=$ $3.9 \mathrm{mN} / \mathrm{m}$ (image $2 \mathrm{j}$ ). The image did not show spot-type pattern as observed at image $2 \mathrm{e}$ of $\mathrm{x}_{\mathrm{DMPC}}=0.2$. Image 21 showed a homogeneous bright contrast. These images resembled with those of pure DMPC monolayer. At $\mathrm{x}_{\mathrm{DMPC}}=0.6$ (Fig. $2 \mathrm{~m}-\mathrm{o}$ ), the images resembled with those of pure DMPC monolayer (2p-r) and similar to those of $\mathrm{x}_{\mathrm{DMPC}}=0.5$. Image $2 \mathrm{~m}$ of $\pi=3.8 \mathrm{mN} / \mathrm{m}$ showed a homogeneous dark contrast. Image $2 \mathrm{n}$ of $\pi=28.6 \mathrm{mN} / \mathrm{m}$ showed brighter image than that of $\pi=3.8 \mathrm{mN} / \mathrm{m}$ (image $2 \mathrm{~m}$ ). Image 20 of $\pi$ $=40.0 \mathrm{mN} / \mathrm{m}$ showed a homogeneous bright contrast. The results of BAM observation suggested that the formation process of DPPC-DMPC mixed monolayer changed with an increase in mole fraction of DMPC.

\section{Compression Moduli}

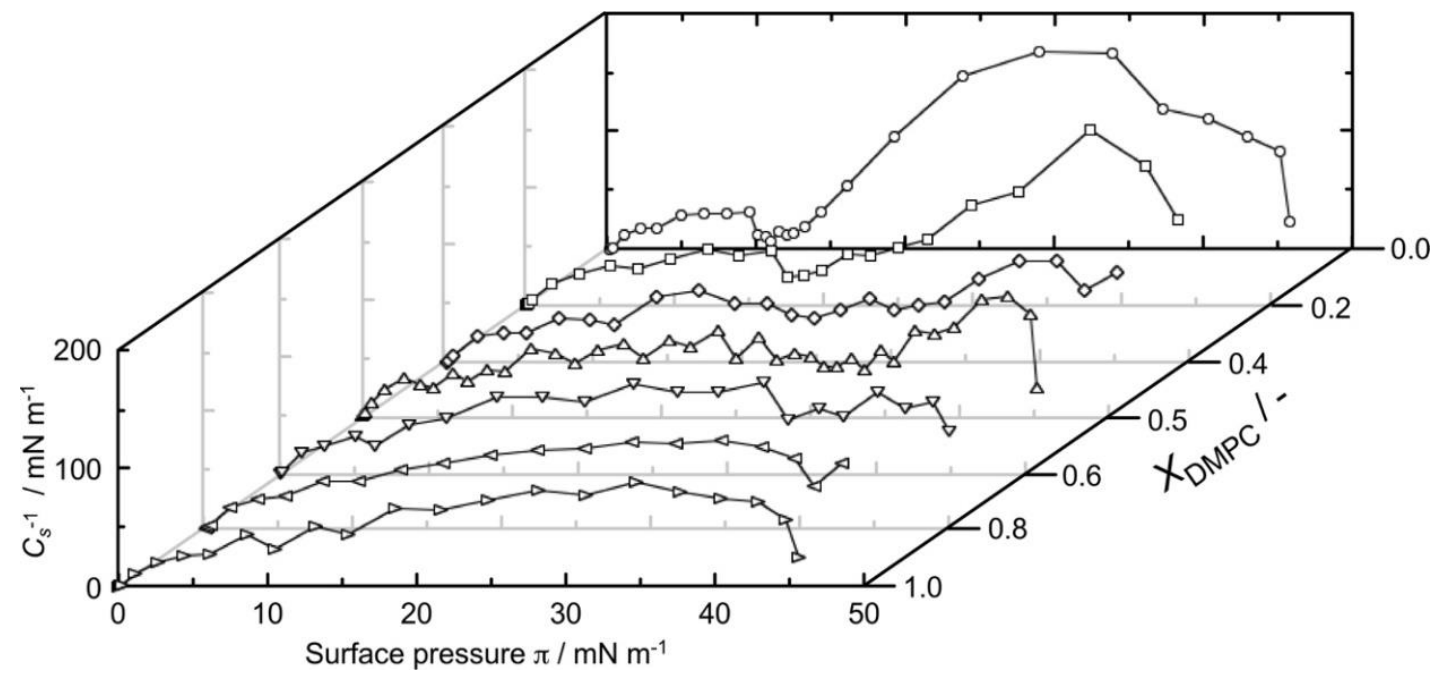

Fig. $3 C_{s}^{-1}-\pi$ profiles of various DPPC-DMPC mixed monolayers (DMPC mole fraction $x_{D M P C}=0.0,0.2,0.4,0.5,0.6,0.8$, and 1.0 ) calculated from the $\pi-A$ isotherm curves in Fig. 1.

In order to obtain more detailed information from the obtained $\pi-A$ isotherm curves (Fig. 1) and BAM observations (Fig. 2), the compression moduli $\left(C_{s}^{-1}\right)$ have been calculated for each $\pi-A$ isotherm curves (Fig. 1). $C_{s}^{-1}$ is described by the following formula,

$$
C_{s}^{-1}=-A(\mathrm{~d} \pi / \mathrm{d} A)
$$

where $A$ is the molecular area $\left(\mathrm{nm}^{2} /\right.$ molecule $), \pi$ is the surface pressure $(\mathrm{mN} / \mathrm{m})$. The values of compression moduli are used conventionally as a tool for considering the physicochemical state of a Langmuir monolayer [29]-[32]. The monolayer state is distinguished in following states; gaseous (G), liquid expanded (LE), liquid condensed (LC), and solid (S). The values of $C_{s}^{-1}:<12,12-100,100-250$, and $>250 \mathrm{mN} / \mathrm{m}$ corresponded to G, LE, LC, and S state.

Fig. 3 shows $C_{s}^{-1}$ versus $\pi$ profiles of various DPPC-DMPC mixed monolayers of $x_{D M P C}=0.0,0.2,0.4$, $0.5,0.6,0.8$, and 1.0 on the water surface at $26{ }^{\circ} \mathrm{C}$. Horizontal axis represents $\pi$, vertical axis represents calculated $C_{s}^{-1}$ parameter values, and depth axis is $x_{D M P C}$. At the pure DPPC monolayer $\left(x_{D M P C}=0.0,(\mathrm{O})\right)$, there were two processes. At first process, the $C_{s}^{-1}$ value increased gradually until around $10 \mathrm{mN} / \mathrm{m}$. The maximum $C_{s}^{-1}$ value was $25 \mathrm{mN} / \mathrm{m}$ and referred to LE state. At second process after showing a steep dip corresponding to LE-LC transition $(10 \mathrm{mN} / \mathrm{m})$, the $C_{s}^{-1}$ value increased again until $34 \mathrm{mN} / \mathrm{m}$. The rate of 
the increase was larger than that of first process. Maximal $C_{s}^{-1}$ value was $170 \mathrm{mN} / \mathrm{m}$ and referred to $\mathrm{LC}$ state. With decrease in the value more than $34 \mathrm{mN} / \mathrm{m}$, monolayer formation was completed. This profile is a characteristic of a monolayer causing two-dimensional phase transition (LE-LC transition). The maximum $C_{s}^{-1}$ value $(170 \mathrm{mN} / \mathrm{m})$ of second process was smaller than the value $(220 \mathrm{mN} / \mathrm{m})$ obtained by the compression method [22], [33]. This indicates that the DPPC monolayer formed by the dropping method is "semi-expanded state" type monolayer as mentioned in the section 3.1 ( $\pi-A$ isotherm).

At the pure DMPC monolayer $\left(x_{D M P C}=1.0,(\triangleright)\right)$, there was one process different from that of DPPC monolayer (O). The $C_{s}^{-1}$ value increased gradually and monotonically until $35 \mathrm{mN} / \mathrm{m}$. With decrease in the value more than $35 \mathrm{mN} / \mathrm{m}$, monolayer formation was completed. The maximum $C_{s}^{-1}$ value was ca. $90 \mathrm{mN} . \mathrm{m}$ and referred to LE state. This profile is a characteristic of a LE monolayer, different from that of pure DPPC monolayer. The maximal $C_{s}^{-1}$ value $(90 \mathrm{mN} / \mathrm{m})$ was a little smaller than the value $(100$ $\mathrm{mN} / \mathrm{m}$ ) obtained by the compression method [33]. This indicates that the DMPC monolayer by the dropping method is certainly LE type as mentioned in section 3.1 ( $\pi-A$ isotherm).

The shape of $C_{s}^{-1}-\pi$ profiles of DPPC-DMPC mixed monolayer changed gradually according to an increase in the mole fraction of DMPC from 0.2 to 0.8 as following. At $x_{D M P C}=0.2$ ( $\square$ ), there were two processes similar to that of pure DPPC monolayer of $x_{D M P C}=0.0$. At the first process, the $C_{s}^{-1}$ value increased gradually until $17 \mathrm{mN} / \mathrm{m}$ and reached a maximal value of $50 \mathrm{mN} / \mathrm{m}$ and referred to LE state. This process overlapped and became extension of DPPC monolayer. This indicated that the tendency of LE state is stronger than that of pure DPPC monolayer. At the second process where a steep dip corresponding to LE-LC transition of mixed monolayer was noticed, the value increased again until $39 \mathrm{mN} / \mathrm{m}$. The rate of the increase after the dip was similar to that of DPPC monolayer. The maximal value reached to $150 \mathrm{mN} / \mathrm{m}$ and referred to LC state. This value remained lower than that of pure DPPC monolayer of the second increased process. With decrease in the value more than $39 \mathrm{mN} / \mathrm{m}$, monolayer formation was completed. This result was a little different from that of pure DPPC monolayer. This indicates that the rigidly of DPPC-DMPC mixed monolayer of $x_{D M P C}=0.2$ was reduced by mixing LEtype DMPC molecules. In other words, increase in elasticity was noticed compared to pure DPPC monolayer. At $x_{D M P C}=0.4(\diamond)$, there were two processes different from those of less than $x_{D M P C}=0.2$. At first process, the $C_{s}^{-1}$ value increased gradually until $17 \mathrm{mN} / \mathrm{m}$. The maximum value was $50 \mathrm{mN} / \mathrm{m}$ and referred to LE state. This process is similar to those of less than $x_{D M P C}=0.2$. At the second process noticed at $17 \mathrm{mN} / \mathrm{m}$, on the other hand, the $C_{s}^{-1}$ decreased and increased gently until $33 \mathrm{mN} / \mathrm{m}$, and subsequent increased faster until $40 \mathrm{mN} / \mathrm{m}$. The gentle decrease process was different from the steep dip at less than $x_{D M P C}=0.2$. The LE-LC transition observed at less than $x_{D M P C}=0.2$, has not occurred. With decrease in the value more than $40 \mathrm{mN} / \mathrm{m}$, monolayer formation was completed. The maximum $C_{s}^{-1}$ value of the second process was $90 \mathrm{mN} / \mathrm{m}$ and referred to LE state. This indicates that the mixed monolayer of $x_{D M P C}=0.4$ changed from elastic state of $x_{D M P C}=0.2$ into semi-expand state. At $x_{D M P C}=0.5(\triangle)$, there were two processes similar to $x_{D M P C}=0.4$. At first process, the $C_{s}^{-1}$ value increased gradually until around $25 \mathrm{mN} / \mathrm{m}$. The maximum value was $60 \mathrm{mN} / \mathrm{m}$ and referred LE state. At the second process more than $25 \mathrm{mN} / \mathrm{m}$, the $C_{s}^{-1}$ decreased and increased gently until $36 \mathrm{mN} / \mathrm{m}$, and subsequent increased faster until $42 \mathrm{mN} / \mathrm{m}$. With decrease in the value more than $42 \mathrm{mN} / \mathrm{m}$, monolayer formation was completed. The maximum $C_{s}^{-1}$ value of the second process was $100 \mathrm{mN} / \mathrm{m}$ and referred to LE state. This process was similar and a slight shift to the right compared to that of $x_{D M P C}=0.4$. This indicates that the mixed monolayer of semi-expand state was promoted at $x_{D M P C}=0.5$ compared to the state of $x_{D M P C}=0.4$. At $x_{D M P C}=0.6(\nabla)$, there was a different process compared to those of $x_{D M P C}=0.4$ and 0.5 . At less than $32 \mathrm{mN} / \mathrm{m}, C_{s}^{-1}$ value increased gradually resembled to those of $x_{D M P C}=0.2,0.4$, and 0.5 . The maximum value was $80 \mathrm{mN} / \mathrm{m}$ and referred to LE state. After showing the steep dip and the minimum $C_{s}^{-1}$ value of $50 \mathrm{mN} / \mathrm{m}$ at $33 \mathrm{mN} / \mathrm{m}$, the value increased gently and the monolayer formation was completed with decrease in the value at $45 \mathrm{mN} / \mathrm{m}$. The slop of the increase was similar to that of gentle increase in the second process of $x_{D M P C}=0.2$ and 0.4 . This indicates that the mixed monolayer of $x_{D M P C}=0.6$ changed from semi-expand state of $x_{D M P C}=0.5$ into expand state. At $x_{D M P C}=0.8(\triangleleft)$, there was one process similar to that of $x_{D M P C}=1.0$. The $C_{s}^{-1}$ value increased gradually and monotonously until $35 \mathrm{mN} / \mathrm{m}$. With decrease in the value more than $35 \mathrm{mN} / \mathrm{m}$, monolayer formation was completed. The maximum $C_{s}^{-1}$ value was $75 \mathrm{mN} / \mathrm{m}$ and referred to LE state. This indicates that the mixed monolayer of $x_{D M P C}=0.8$ is certainly in an expand state, in other words, LE monolayer. These results of $C_{s}^{-1}$ parameters suggest that an increase in $x_{D M P C}$ changes dynamically the state of DPPC-DMPC mixed monolayer.

\section{Mole Fraction of DMPC ( $\left.x_{D M P C}\right)$ Dependence of $A_{0}$}

$A_{0}$ s of DPPC-DMPC mixed monolayers were compared to those of ideal mixed monolayers calculated from each $A_{0}$ of DPPC and DMPC monolayers. Fig. 4a $(\bigcirc)$ shows $x_{D M P C}$ dependence of $A_{0}$ derived from $\pi-A$ isotherm curves in Fig. 1 . The horizontal axis represents $x_{D M P C}$ and the vertical axis represents $A_{0}$ of 
each $x_{D M P C}$. The $x_{D M P C}=0.0$ and 1.0 are pure DPPC and DMPC monolayers, respectively. The dotted line is drawn as an ideal additivity to each $x_{D M P C}$.

At $x_{D M P C}=0.2$, the value of $A_{0}$ was almost the same as that of $x_{D M P C}=0.0$ similar pattern noticed in $\pi$ $A$ Isotherm (section 3.1) and also showed a negative deviation from the ideal value. This indicates that the flexible alkyl chain of DMPC molecule at $x_{D M P C}=0.2$ was affected by the rigid alkyl chain of DPPC molecule. At $x_{D M P C}=0.4$ and 0.5 , the values of $A_{0} \mathrm{~s}$ were overlapped with the ideal (dotted) line. In these mole fractions DPPC and DMPC molecules mixed ideally. Therefore, both molecules existed in a state where they do not interact with each other in the mixed monolayer. At $x_{D M P C}=0.6$ and 0.8 , on the other hand, the values of $A_{0}$ s were almost the same as that of monolayer of $x_{D M P C}=1.0$ similar to noticed in the $\pi-A$ isotherm curve (Section III, A) and also showed a positive deviation from the ideal value. This indicates that the rigid alkyl chain of DPPC molecule at $x_{D M P C}=0.6$ and 0.8 was affected by the flexible alkyl chain of DMPC molecule on the contrary to the case of $x_{D M P C}=0.2$.

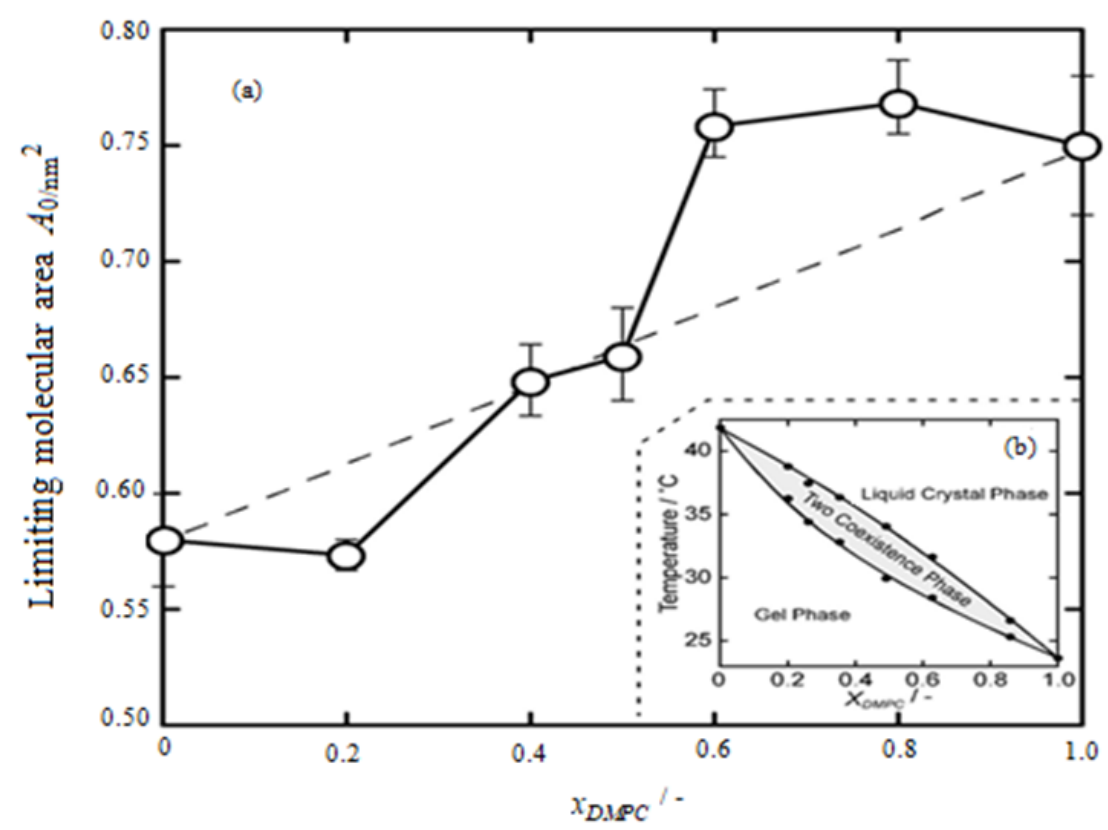

Fig. 4 (a) $x_{D M P C}$ dependence of $A_{0}$ derived from the $\pi-A$ isotherm curves in Fig. 1 . The dotted line is drawn as an ideal additivity on each $x_{D M P C}(\mathrm{~b})$ phase diagram at various mixing ratio of DPPC and DMPC bulk phase (multilamellar vesicle in water).

The above dependence of $A_{0} \mathrm{~s}$ on $x_{D M P C}$ was specific to the DPPC-DMPC mixed monolayer and different from that of other mixed monolayers such as DPPC-Chol (Chol: cholesterol) and DMPC-Chol monolayers which had a negative deviation from the ideal value appeared due to the condensation effect of Chol as reported in the earlier studies [18], [22], [24], [26], [34], [35]. The results obtained from $A_{0}$ versus $x_{D M P C}$ plot of DPPC-DMPC monolayer will help to understand the macroscopic phase diagram of DPPC-DMPC mixture. Fig. 4b inserted in Fig. 4a shows a phase diagram prepared from observations of mixing DPPC and DMPC in different ratios forming multilamellar vesicle in water. The phase diagram was constructed from the transition curves observed by differential scanning calorimetry (DSC) [7], [8]. The horizontal axis represents $x_{D M P C}$ and the vertical axis represents the phase transition temperature at various $x_{D M P C}$. On the temperature range 24 to $41{ }^{\circ} \mathrm{C}$, DPPC-DMPC mixture (vesicle) is transferred from the gel phase to the liquid-crystal phase via the two-phase coexistence region with an increase in $x_{D M P C}$. It is well known that alkyl chains in vesicle are in a state close to crystal state (all-trans type) in the gel phase, a state close to liquid (gauche type) in the liquid-crystal phase, a mixed state including both gel and liquid-crystal phases exists in coexistence region [1], [4], [7]-[11]. The 3-dimensional macroscopic phase diagram is not always enough to explain 2-dimensional monolayer state. The specific $x_{D M P C}$ dependence of $A_{0}$ observed in mixed monolayer is related to the macroscopic phase diagram. Therefore, the mixed monolayer of less than $x_{D M P C}=0.2$ corresponds to a gel-type state. Those at $x_{D M P C}=0.4$ and 0.5 fit to the ideal (dotted) line in the Fig. 4a corresponds to a two-phase coexistence state. That at more than $=0.6$ corresponds to a liquid-crystal type state. Based on the above description, the temperature $\left(26.0^{\circ} \mathrm{C}\right)$ of the state transfer at the mixed monolayer was lower than that shown in the macroscopic phase diagram $\left(33{ }^{\circ} \mathrm{C}\right)$ in Fig. 4b. As for this difference, Kajiyama et al. [36] have reported that the melting point of twodimensional crystalline monolayer of several fatty acids was lower than that of their three-dimensional bulk crystalline states. Therefore, the above temperature difference appears as a difference in dimension. 

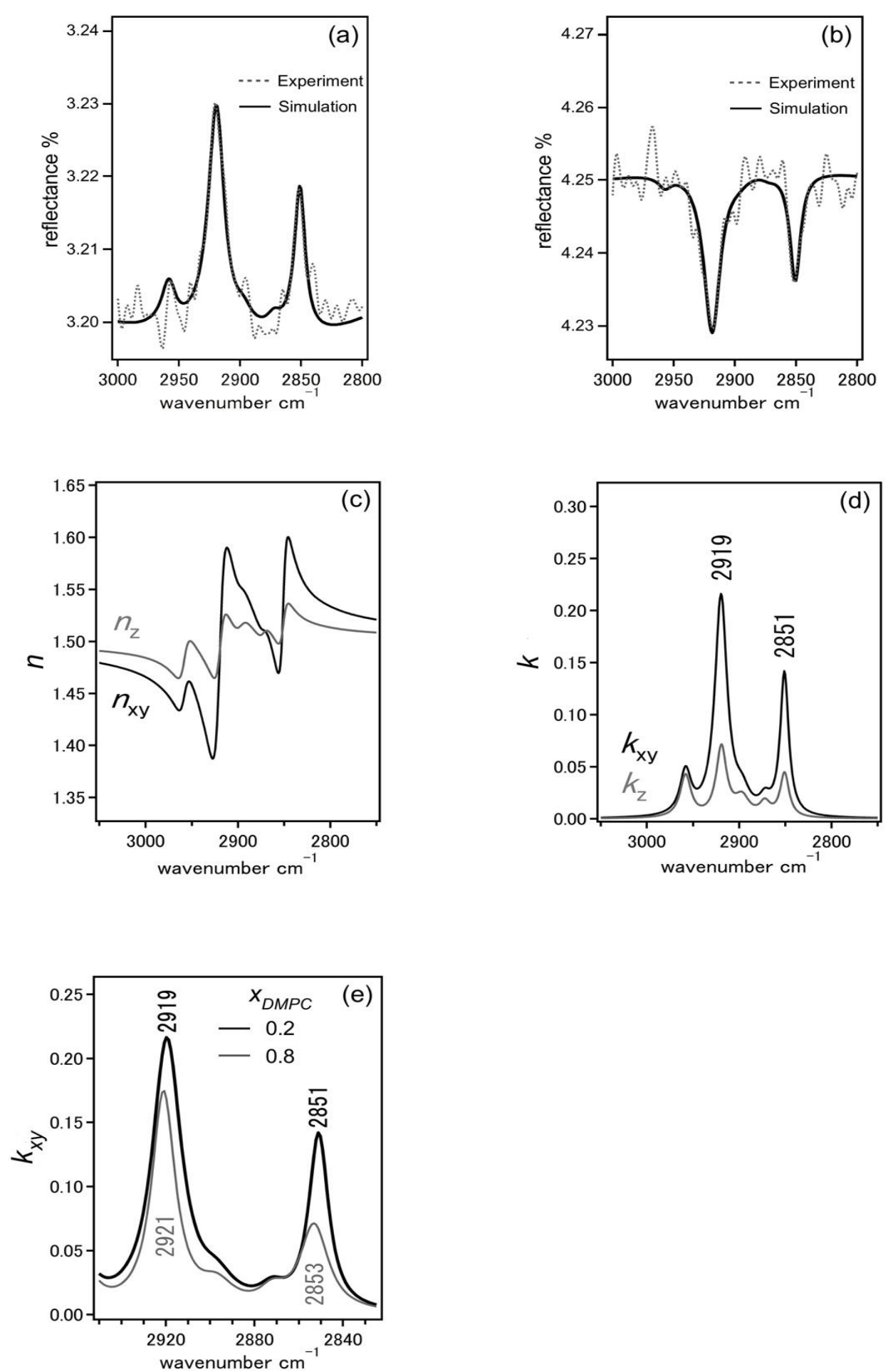

Fig. 5(a-e) IER spectra of DPPC-DMPC mixed monolayer of $x_{D M P C}=0.2$ and 0.8 at around a pressure of $38 \mathrm{mN} / \mathrm{m}$ in Fig. 1; incident angle is $8^{\circ}$ (a) and $70^{\circ}(\mathrm{b})$; dotted-line is measured spectrum and solid-line is the simulated spectrum; for $x_{D M P C}=0.2$. $(\mathrm{c}, \mathrm{d})$ : wavenumber dependence of complex refractive index $\left(n+k_{i}\right)$, n-spectrum of real part (c) and $k$-spectrum of imaginary part (d), for $x_{D M P C}=0.2$. (d) is also absorption spectra $\left(k\right.$-spectra); (e) kxy-spectra of $x_{D M P C}=0.2$ (black line) and $x_{D M P C}=0.8$ (gray line) for comparison.

\section{E. Infrared External Reflection Spectroscopy (IERS)}

To investigate the molecular-level state based on the specific $x_{D M P C}$ dependence of $A_{0}$ in Fig. $4 \mathrm{a}$, we have performed the IERS measurement of DPPC-DMPC mixed monolayers in two mole fraction ratios of $x_{D M P C}=0.2$ and 0.8 , to study the alkyl chain conformation structure of DPPC and DMPC molecules. Fig. $5 \mathrm{a}$ and $\mathrm{b}$ show IER spectra of DPPC-DMPC mixed monolayer of $x_{D M P C}=0.2$ at a pressure of $38 \mathrm{mN} / \mathrm{m}$, measured at an incident angle of $8^{\circ}$ (Fig. 5a) and $70^{\circ}$ (Fig. 5b). The horizontal axis represents wavenumber $\left(\mathrm{cm}^{-1}\right)$ and the vertical axis is reflectance (\%). In both Fig. 5a and b, dotted-line shows measured spectrum and solid-line is simulated spectrum. More, their two lines are offset to overlay the 
experimental and simulated values. Fig. 5c and d show wavenumber dependence of complex refractive index $\left(n+k_{i}\right)$ of the mixed monolayer obtained from the above simulated calculation. Fig. $5 \mathrm{c}$ is $\mathrm{n}-$ spectrum of real part and Fig. 5d is k-spectrum of imaginary part. Moreover, Fig. $5 \mathrm{~d}$ corresponds to the absorption spectra $\left(k\right.$-spectra). The horizontal axis represents wavenumber $\left(\mathrm{cm}^{-1}\right)$ and the vertical axis represents intensity of each real and imaginary part, indicating the components of parallel to the surface plane (in plane) by black lines $\left(n_{x y}, k_{x y}\right)$ and the components perpendicular to the surface plane (out of plane) by gray lines $\left(n_{z}, k_{z}\right)$ (Yamamoto et al. 2008). Fig. 5e shows the absorption spectra $\left(k_{x y}\right.$-spectra) of $x_{D M P C}=0.2$ (black line) and $x_{D M P C}=0.8$ (gray line). The same analysis of $x_{D M P C}=0.2$ has been also performed about $x_{D M P C}=0.8$. On Fig. $5 \mathrm{e}$, the horizontal axis represents wavenumber $\left(\mathrm{cm}^{-1}\right)$ and the vertical axis represents the absorption spectra of each $k_{x y}$ (in plane) of $x_{D M P C}=0.2$ and 0.8 . After that, we will discuss $k_{x y}$ spectra that appeared clearly by the IERS measurement for comparison of $x_{D M P C}=0.2$ and 0.8 .

On the $k_{x y}$-spectra (Fig. 5e) at $x_{D M P C}=0.2$ (black line), two absorption peaks at $2919 \mathrm{~cm}^{-1}$ and $2851 \mathrm{~cm}^{-}$ ${ }^{1}$ were selected for simulation. These peaks were assigned to $\mathrm{CH}_{2}$ anti-symmetric stretching vibration band $v_{\text {as }}\left(\mathrm{CH}_{2}\right)$ and $\mathrm{CH}_{2}$ symmetric stretching vibration band $v_{\mathrm{s}}\left(\mathrm{CH}_{2}\right)$, respectively. Two peaks at $2919 \mathrm{~cm}^{-}$ ${ }^{1}$ and $2851 \mathrm{~cm}^{-1}$ were strong in particular. These two peaks were of the methylene groups in the two long alkyl chains of DPPC and DMPC molecules. As reported previously [21], [37], it is known that when the alkyl chain has a structure which contains trans conformation to a certain degree in the chain, two $v_{\mathrm{as}}\left(\mathrm{CH}_{2}\right)$ and $v_{\mathrm{s}}\left(\mathrm{CH}_{2}\right)$ bands of methylene group in the chain are assigned to $2919 \mathrm{~cm}^{-1}$ and $2851 \mathrm{~cm}^{-1}$ bands, respectively. In the case of pure DPPC monolayer at $26{ }^{\circ} \mathrm{C}$, we reported that two peak positions of those $v_{\text {as }}\left(\mathrm{CH}_{2}\right)$ and $v_{\mathrm{s}}\left(\mathrm{CH}_{2}\right)$ bands at $\pi=42 \mathrm{mN} / \mathrm{m}$ were shown at $2919 \mathrm{~cm}^{-1}$ and $2851 \mathrm{~cm}^{-1}$ and those alkyl chains stood toward to normal of monolayer surface [16]. In the case of pure DMPC monolayer at $26{ }^{\circ} \mathrm{C}$, on the other hand,two $v_{\mathrm{as}}\left(\mathrm{CH}_{2}\right)$ and $v_{\mathrm{s}}\left(\mathrm{CH}_{2}\right)$ bands of methylene group of alkyl chain of DMPC molecule are assigned to $2920 \mathrm{~cm}^{-1}$ and $2852 \mathrm{~cm}^{-1}$ bands, respectively, and contains kinked form (gauche conformation) in the chain [24]. It is suggested that the form of the two alkyl chains in the DPPC and DMPC molecules in the mixed monolayer are straightened regularly. Therefore, the result indicates that the kinked form of alkyl chain of DMPC molecule decreased and the structural transition from gauche- to trans- conformation was caused by the presence of DPPC molecule. In other words, DMPC molecules of $x_{D M P C}=0.2$ had a stable and condensed structure like pure DPPC molecules, which did not disturb the mixed monolayer structure. These results correspond to the value of $A_{0}$ of $x_{D M P C}=0.2$ in Fig. $4 \mathrm{a}$ was almost the same as that of $x_{D M P C}=0.0$.

On the $k_{x y}$-spectra (Fig. 5e) at $x_{D M P C}=0.8$ (gray line), two absorption peaks at $2921 \mathrm{~cm}^{-1}\left(v_{\mathrm{as}}\left(\mathrm{CH}_{2}\right)\right)$ and $2853 \mathrm{~cm}^{-1}\left(v_{\mathrm{s}}\left(\mathrm{CH}_{2}\right)\right)$ were selected for the simulation. These peaks were also assigned to $v_{\text {as }}\left(\mathrm{CH}_{2}\right)$ and $v_{\mathrm{s}}\left(\mathrm{CH}_{2}\right)$, respectively, as same as those of $x_{D M P C}=0.2$. These two peaks were mainly due to the methylene groups in the two long alkyl chains in the DPPC and DMPC molecules. These peaks showed more high wavenumber on both $v_{\text {as }}\left(\mathrm{CH}_{2}\right)$ and $v_{\mathrm{s}}\left(\mathrm{CH}_{2}\right)$ bands $\left(2921 \mathrm{~cm}^{-1}\right.$ and $\left.2853 \mathrm{~cm}^{-1}\right)$, compared to previous reported peak positions $\left(2920 \mathrm{~cm}^{-1}\right.$ and $\left.2852 \mathrm{~cm}^{-1}\right)$. Therefore, the result indicates that DPPC-DMPC mixed monolayer at $x_{D M P C}=0.8$ contains irregular structure (gauche conformation) to a large degree in both DMPC and DPPC alkyl chains. In other words, it means that two alkyl chains in DPPC molecules at $x_{D M P C}=0.8$ are also the structure containing gauche conformation. These results correspond to that the value of $A_{0}$ of $x_{D M P C}=0.8$ in Fig. $4 \mathrm{a}$ was almost the same as that of $x_{D M P C}=1.0$.

In order to elucidate the details of the structural difference between DPPC and DMPC molecules in mixed monolayer at $x_{D M P C}=0.2$, we have performed IERS measurement using a dimyristoyl-d54 phosphatidyl choline (DMPC(d)) molecule in which hydrogen atoms of two alkyl chains are deuterated. Fig. 6 shows IER spectra ( $k$-spectra) of DPPC-DMPC(d) mixed monolayer of mole fraction of DMPC(d) $\left(x_{D M P C(d)}\right)=0.2$ at a pressure of $38 \mathrm{mN} / \mathrm{m}$, which were simulated from the two reflectance spectra measured at an incident angle of $8^{\circ}$ and $70^{\circ}$. The horizontal axis represents wavenumber $\left(\mathrm{cm}^{-1}\right)$ and the vertical axis represents the intensity of absorption spectra of each $k_{x y}$ and $k_{z}$. The method of analysis is as same as mixed monolayers of $x_{D M P C}=0.2$ and 0.8 . For comparison, we also added $k$-spectra of $x_{D M P C}=$ 0.2 (Fig. 5d) in Fig. 6. $k_{x y}$ spectra at $x_{D M P C(d)}=0.2$ is shown as continuous black line that of $x_{D M P C}=0.2$ as dotted black line. Similarly, $k_{z}$ spectra at $x_{D M P C(d)}=0.2$ is shown as continuous gray continuous line, that of $x_{D M P C}=0.2$ as dotted gray line. In addition, we have confirmed that $\pi-A$ isotherm curve of $x_{D M P C(d)}=$ 0.2 was the same as that of $x_{D M P C}=0.2$.

On the spectra in Fig. 6, two strong absorption peaks were observed at around $2918 \mathrm{~cm}^{-1}$ and $2850 \mathrm{~cm}^{-1}$. These peaks were assigned to $\mathrm{CH}_{2}$ anti-symmetric stretching vibration band $v_{\mathrm{as}}\left(\mathrm{CH}_{2}\right)$ and $\mathrm{CH}_{2}$ symmetric stretching vibration band $v_{\mathrm{s}}\left(\mathrm{CH}_{2}\right)$, respectively. These two peaks were due to the methylene groups in the two long alkyl chains of only DPPC molecules because peaks of DMPC(d) were another wavenumber region around $2150 \mathrm{~cm}^{-1}$ [38], [39]. Actually, the peak intensity of two $\mathrm{CH}_{2}$ stretching vibration bands certainly decreased as shown by two downward arrows (black and gray). We focused the above two arrows. The decrease in peak intensity of $v_{\mathrm{s}}\left(\mathrm{CH}_{2}\right)$ around $2850 \mathrm{~cm}^{-1}$ was observed only in the $k_{x y}$ spectra 


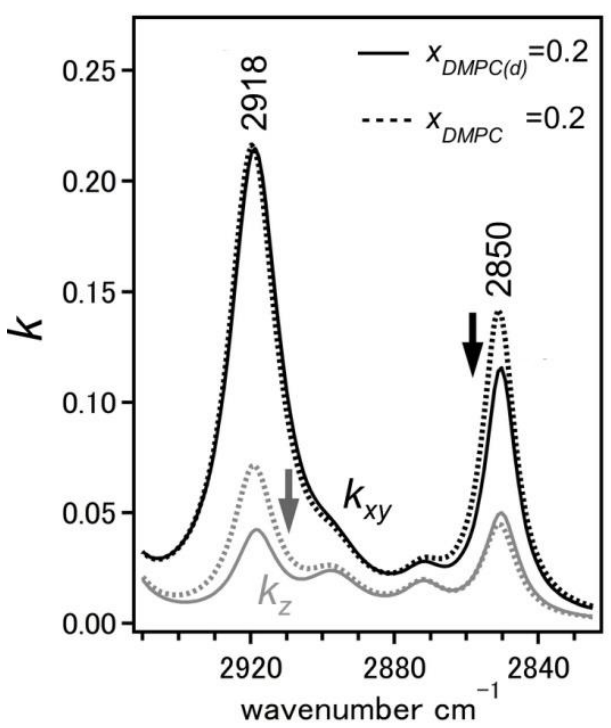

Fig. 6. k-spectra of DPPC-DMPC(d) mixed monolayer of $\mathrm{x}_{\mathrm{DMPC}(d)}=0.2$ at around a pressure of $38 \mathrm{mN} / \mathrm{m}$ (continuous line), containing k-spectra of $x_{D M P C}=0.2$ in Fig. $5 \mathrm{~d}$ (dotted line) for comparison.

of black line and not in that of gray line. The decrease in peak intensity of $v_{\text {as }}\left(\mathrm{CH}_{2}\right)$ at around $2918 \mathrm{~cm}^{-1}$, on the other hand, was observed only in the $k_{z}$ spectra of gray line and not in that of black line. Yamamoto et al. have reported using infrared reflection absorption spectroscopy (IRAS) [40] . that the molecular orientation of $n$-alkane tetratetracontane (TTC, $n$ - $\mathrm{C}_{44} \mathrm{H}_{90}$ ) vacuum-deposited on the Au substrate showed "flat-on" structure of all-trans conformation (molecular skeleton plane) in first TTC layer on Au surface. Applying this analytical method, our results indicate that two alkyl chains in DMPC molecule that occupy $20 \%\left(x_{D M P C}=0.2\right)$ in DPPC-DMPC mixed monolayer orient parallel to the water surface and molecular skeleton planes are also parallel to the surface (flat-on orientation). The orientation of DMPC molecules in the mixed monolayer is in contrast to that of DPPC molecules whose alkyl chains are nearly perpendicular to the surface. This indicates that the mixed monolayer mainly composed of DPPC molecules $\left(x_{D M P C}=0.2\right)$ has a structure that can contain $20 \%$ DMPC molecules in the monolayer while maintaining its stable structure, despite the difference in the orientation between DPPC and DMPC molecules.

\section{CONCLUSION}

In this research, we have investigated the morphology of DPPC-DMPC mixed monolayer formed by the dropping method. The $\pi-A$ isotherm curves by STm on various DPPC-DMPC mixed monolayer showed that the addition of DMPC to the DPPC monolayer at less than $x_{D M P C}<0.4$ retained condensed state like pure DPPC monolayer whereas expandable state like pure DMPC monolayer existed at more than $x_{D M P C}>0.6$. The BAM observation also supported STm results; the images at $x_{D M P C}<0.4$ brightened gradually with increase in dropping volume, followed by bright and dark contrast and finally brightening of image noticed. At $x_{D M P C}>0.5$, the image gradually became brighter until the completion of monolayer. Moreover, IER spectra showed the structural transition (gauche- to trans-conformation) of alkyl chains in DMPC molecule by the rigid structured DPPC molecule at $x_{D M P C}=0.2$, and the structural retention (gauche conformation) of alkyl chains in both DPPC and DMPC molecules at $x_{D M P C}=0.8$ was found. These results indicate that the three-dimensional bulk structural properties of DPPC-DMPC mixture are also reflected at the two-dimensional DPPC-DMPC mixed monolayer level on the water surface.

\section{REFERENCES}

[1] Shimabayashi S, Terada H, Okabayashi H. Biocolloid 1 \&2. Hirokawa Publishing, Tokyo; 1990.

[2] Singer SJ, Nicolson GL. The Fluid Mosaic Model of the Structure of Cell Membranes, Science. 1972;175:720-731.

[3] Gennis RG. Biomembrane, molecular structure and function. SPRINGER, New York. 1990.

[4] Hatta I, Murata M. Dynamics of Biomembrane. Kyoritsu Shuppan Co., Ltd., Tokyo; 2000.

[5] Matsuki H, Goto M, Tamai N.. Membrane States of Lipids in Biological Membranes - Structure-Function Relationship Revealed from Pressure Study. Review of High Pressure Science Technology. 2013;23:30-38.

[6] Mingotaud AF, Mingotaud C, Patterson LK. Handbook of monolayers. Vol. 1\&2, ACADEMIC PRESS, San Diego. 1993.

[7] Mabrey S, Sturtevant JM. Investigation of Phase Transitions of Lipids and Lipid Mixtures by High Sensitivity Differential Scanning Calorimetry. Proceedings of the National Academy of Sciences of the United States of America. 1976;73:3862-3866.

[8] Luna EJ, McConnell HM. Multiple Phase Equilibria in Binary Mixtures of Phospholipids. Biochimica et Biophysica Acta, 
1978;509:462-473.

[9] Caffrey M, Hing FS. A Temperature Gradient Method for Lipid Phase Diagram Construction Using Time-Resolved X-Ray Diffraction. Biophysics Journal. 1987;51:37-46.

[10] Poghosyan AH, Gharabekyan HH. Molecular Dynamics Simulation of DMPC/DPPC Mixed Bilayers, International Journal of Modern Physics C. 2007;18:73-89.

[11] González-Henríquez CM, Villegas-Opazo VA, Sagredo-Oyarce DH, Sarabia-Vallejos MA, Terraza CA. Thermal Response Analysis of Phospholipid Bilayers Using Ellipsometric Techniques. Biosensors. 2017;7:34.1-17.

[12] Rufeil-Fiori E, Wilke N, Banchioa AJ. Dipolar interactions between domains in lipid monolayers at the air-water interface. Soft Matter.2016;12:4769-4776.

[13] Arnold A, Cloutier I, Ritcey AM, Auger M. Temperature and pressure dependent growth and morphology of DMPC/DSPC domains studied by Brewster angle microscopy. Chemistry and Physics of Lipids. 2005;133:165-179.

[14] Matsuo H, Motomura K, Matsuura R. Mixed Monolayers of Dipalmitoylglycerophophocholine, Distearoylglycerophosphocholine and 1- Palmitoylglycerol. Chemistry and Physics of Lipids. 1982;31:53-60.

[15] Lawrie GA, Gentle IR, Barnes GT. The structure of mixed monolayer films of DPPC and hexadecanol. Colloids and Surfaces A: Physicochemical and Engineering Aspects, 2000;171:217-224.

[16] Yoshida D, Yokoyama T, Shimoaki T, Tomita T, Yoshida T, Yamamoto Y, Taga K, Sumino A, Dewa T, Nango M, Yamamoto M, Sheravani Z. Morphology observation of dipalmitoyl phosphatidyl choline (DPPC) monolayer on water surface by dropping method. Journal of Biophysical Chemistry. 2013;4:115-121.

[17] Yamamoto Y, Taga K.. Lipid Monolayer and Interaction with Anesthetics. Encyclopedia of Biocolloid and Biointerface Science. 2016;1:36-58.

[18] Yokoyama T, Yoshida D, Mori H, Okabe M, Shervani Z, Taga K, Yamamoto Y, Sumino A, Dewa T, Nango M, Yamamoto M. Morphological Observation of Specific Condensation Effect of Cholesterol on Dipalmitoyl Phosphatidyl Choline (DPPC) Monolayer by Dropping Method. Journal of Biophysical Chemistry. 2016;7:98-109.

[19] Kobayashi Y, Amano T, Taga K, Yamamoto Y, Shervani Z, Yamamoto M. Surface Properties of Novel Surfactant, Dihexadecyl Gemini Phosphate, Monolayers on Water Surface by Dropping Method. Journal of Biophysical Chemistry. 2017;8:39-50.

[20] Okabe M, Taga K, Yoshino A, Yamamoto Y, Taneda A, Shinoda S, Kanamasa S, Shervani Z.. Effect of Escherichia coli on phospholipid monolayers: surface tensiometry and Brewster angle microscopy measurements. European Biophysics Journal. 2020;49:71-84.

[21] Yamamoto M, Suzuki M, Kimura T, Itoh K. Molecular structures at free surfaces of liquid n-heptadecane investigated by infrared external reflection spectroscopy. The Journal of Physical Chemistry C. 2008;112:13232-13239.

[22] Ohe C, Sasaki T, Noi M, Goto Y, Itoh K. Sum Frequency Generation Spectroscopic Study of the Condensation Effect of Cholesterol on a Lipid Monolayer. Analytical and Bioanalytical Chemistry. 2007;388:73-79.

[23] Yamamoto Y, Yokoyama T, Yoshida D, Mori H, Sekiguchi K, Shimoaki T, Yoshio A, Taga K, Shervani Z, Yamamoto M. Interactions between Phospholipid Monolayers (DPPC and DMPC) and Anesthetic Isoflurane Observed by Quartz Crystal Oscillator. Journal of Biophysical Chemistry. 2015;6:42-53.

[24] Ito D, Ikeda T, Taga K, Yamamoto Y, Shervani Z, Yamamoto M. Structural Change of Two Alkyl Chains in DMPC Molecule on DMPC- Cholesterol Mixed Monolayer -Specific Addition Effect of Cholesterol-. Journal of Biophysical Chemistry. 2019;10:15-29.

[25] Nakagaki M, Tomita K, Handa T. Interaction of Differently Oriented Lipids in Monolayer: Mixed Monolayers of 16-(9Anthroyloxy) palmitic Acid with Phosphatidylcholine and Cholesterol. Biochemistry.1985;24:4619-4624.

[26] Janout V, Turkyilmaz S, Wang M, Wang Y, Manaka Y, Regen SL.. An Upside Down View of Cholesterol's Condensing Effect: Does Surface Occupancy Play a Role ?. Langmuir. 2010;26:5316-5318.

[27] Burn A, Brezesinsuki G, Möhwald H, Blanzat M, Perez E, Rico-Lattes I. Interaction between phospholipids and new Gemini catanionic surfactants having anti-HIV activity. Colloids and Surfaces A: Physicochemical and Engineering Aspects.2003;228:3-16.

[28] Yassine W, Milochau A, Buchoux S, Lang J, Desbat B, Oda R. Effect of monolayer lipid charges on the structure and orientation of protein VAMP1 at the air-water interface. Biochimica et Biophysica Acta, 2010;1798:928-937.

[29] Gaines GL. Insoluble monolayers at liquid-gas interface. Interscience Publishers, New York. 1966.

[30] Broniatowski M, Flasinski M, Dynarowicz-Latka P, Majewski J. Grazing Incidence Diffraction and X-ray Reflectivity Studies of the Interactions of Inorganic Mercury Salts with Membrane Lipids in Langmuir Monolayers at the Air/Water Interface. Journal of Physical Chemistry B. 2010;114:9474-9484.

[31] Miyoshi T, Kato S. Detailed Analysis of the Surface Area and Elasticity in the Saturated 1,2Diacylphosphatidylcholine/Cholesterol Binary Monolayer System. Langmuir. 2015;31:9086-9096.

[32] Patterson M, Vogel HJ, Prenner EJ. Biophysical characterization of monofilm model systems composed of selected tear film phospholipids. Biochimica et Biophysica Acta. 2016;1858:403-414.

[33] Sabatini K, Mattila JP, Kinnunen PKJ. Interfacial Behavior of Cholesterol, Ergosterol, and Lanosterol in Mixtures with DPPC and DMPC. Biophysical Journal. 2008;95:2340-2355.

[34] Chapman D, Owens NF, Phillip MC, Walker DA. Mixed Monolayers of Phospholipids and Cholesterol. Biochimica et Biophysica Acta. 1969;183:458-465.

[35] Worthman LAD, Nag K, Davis PJ, Keough KM. Cholesterol in Condensed and Fluid Phosphatidylcholine Monolayers Studied by Epifluorescence Microscopy. Biophysical Journal. 1997;72:2569-2580.

[36] Kajiyama T, Tanimoto Y, Uchida M, Oishi Y, Takei R. Electro Microscopic Studies of Crystalline and Amorphous Monolayers of Fatty Acids. Chemistry Letters, 1989;2:189-192.

[37] Snyder RG, Strauss HL. C-H Stretching Modes and the Structure of n-Alkyl Chains. 1. Long, Disordered Chains. Journal of Physical Chemistry.1982;86:5145-5150.

[38] Knauf K, Meister A, Kerth A, Blume A. Interaction of alkyltrimethylammonium bromides with DMPC-d54 and DMPG-d54 monolayers studied by infrared reflection absorption spectroscopy (IRRAS), Journal of Colloid and Interface Science, 2010;342:243-252.

[39] Grossutti M, Seenath R, Lipkowski JInfrared and Fluorescence Spectroscopic Investigations of the Acyl Surface Modification of Hydrogel Beads for the Deposition of a Phospholipid Coating. Langmuir.2015;31:11598-11604.

[40] Yamamoto M, Sakurai Y, Hosoi Y, Ishii H, Kajikawa K, Ouchi Y, Seki K. Structures of a Long-Chain n-Alkane, n-C44H90, on a $\mathrm{Au}(111)$ Surface: An Infrared Reflection Absorption Spectroscopic Study, Journal of Physical Chemistry B. 2000;104:7363-7369. 